\title{
Los inicios de la prensa portuguesa en los Estados Unidos de América
}

\author{
The beginning of the Portuguese press in the United States of America
}

\section{O início da imprensa portuguesa nos Estados Unidos da América}

\author{
Alberto Pena Rodriguez \\ Doutor (com Menção Europeia) em Ciências da Informação pela Universidade Complutense de Madrid e \\ Doutor em História Contemporânea pela Universidade Nacional de Educación a Distancia (UNED). É professor \\ titular de História da Propaganda na Faculdade de Ciências Sociais e da Comunicação na Universidade de Vigo. \\ <alberto@uvigo.es>
}

\section{RESUMEN}

Este trabajo pretende aproximarse a los inicios de la prensa portuguesa en los Estados Unidos de América, a finales del siglo XIX y principios del XX. Mediante un metodología de carácter cualitativo y cuantitativo, se analiza el surgimiento yexpansión de la prensa luso-americana. El estudio intenta describir los rasgos principalesde este tipo de periódicos para comprender la dimensión y la relevancia del fenómeno periodístico de la comunidad inmigrante portuguesa en Estados Unidos.

Palabras clave: Prensa. Estados Unidos de América. Inmigración Portuguesa.

\section{ABSTRACT}

This paper aims to approach to the Portuguese ethnic press in the United States of America at the end of the nineteenth and early twentieth centuries. By means a qualitative and quantitative methodology, this article analyses the emergence and expansion of the Portuguese press throughout the North American territory. This research tries to describe the main features of this kind of newspapers to understand the relevance and dimension of the Portuguese immigrant journalism in the United States.

Keywords: Press. United States of America. Portuguese Immigration.

\section{RESUMO}

Esse artigo pretende abordar a imprensa de etnia portuguesa nos Estados Unidos no final do século dezenove e começo do século vinte. Através de metodologias quantitativas e qualitativas, esse artigo analisa a emergência e expansão da imprensa portuguesa no território americano. Essa pesquisa tenta descrever as principais características desse tipo de jornal e entender a relevância e a dimensão do jornalismo imigrante português nos EUA.

Palavras-chave: Imprensa. Estados Unidos. Imigração portuguesa.

\section{Introducción}

Este trabajo es el resultado de una investigación interdisciplinar y transnacional que utiliza técnicas cualitativas y cuantitativas para aproximarse al universo de cabeceras periodísticas que los portugueses emigrados a Estados Unidos han producido en uno de los períodos de mayor flujo migratorio hacia América, entre 1880 y 1910, cuando llegaron 106.214 emigrantes originarios de Portugal, según los datos el U.S. Census Bureau de 2012. En este período se fundaron 49 publicaciones periódicas en portugués, sobre todo en los principales 
Estados receptores de emigrantes lusos en aquella época: Massachusetts, California y Hawai (Pena e outros, 2012; Williams, 2007). Algunos de estos periódicos tuvieron ediciones efímeras. Sin embargo, otros se consolidaron y se convirtieron en medios de comunicación relevantes dentro del fenómeno de la prensa étnica norteamericana (Ireland, 1990; Miller, 1987; Park, 1922). La edición del primer periódico portugués, publicado en Erie (Pennsylvania), data de 1877, cuando se fundó el Jornal de Noticias. A partir de entonces Portugal pasó a ser noticia en América y los portugueses se convirtieron, a lo largo de los años, en productores de información, creando sus propios instrumentos de comunicación social y de autorrepresentación pública.

A través de la descripción y análisis de los casos más paradigmáticos, con este abordaje académico se pretende aportar datos, nombres, cifras y episodios relevantes para el conocimiento de la historia de la prensa portuguesa en Estados Unidos. Este estudio forma parte de un proyecto de investigación cuya cobertura cronológica abarca la historia de la presencia portuguesa en Estados Unidos, basada en una muestra documental exhaustiva que reúne un catálogo de 167 publicaciones periódicas editadas en 10 Estados diferentes (Pena e outros, 2015, p. 211-261). ${ }^{1}$

Entre los trabajos publicados hasta ahora sobre diferentes aspectos del fenómeno, destacan particularmente el capítulo publicado por L. Pap sobre la "Portuguese press" en la obra colectiva de S. Miller (1987, p. 291-302); el texto que G. Gomes dedica a la representanción de la política americana en los periódicos portugueses de California, con una rigurosa aproximación a su historia, difundido a través de la revista Gávea Brown (1995, p. 5-90); y el capítulo escrito por R. A. Correia para el libro editado por Holton \& Klimt (2009, p. 227-247) sobre el Diario de Noticias durante los años treinta. Los tres trabajos son contribuciones importantes sobre el tema, pero ninguna de ellas analiza in extenso este objeto de estudio. Sin embargo, es necesario ahondar todavía más, tanto desde abordajes académicos generales como a partir de estudios específicos para compreder la auténtica dimensión periodística, social y cultural de la prensa inmigrante lusa dentro en la historia del periodismo étnico norteamericano, así como su influencia en la colonia portuguesa y su impacto real en la vida social local.

1 El estudio ha contado con la financiación del Center for Portuguese Studies \& Culture de la University of Massachusetts Dartmouth a través de la cátedra Hélio \& Amélia Pedroso/Luso-American Foundation Endowed Chair, así como de la Fundação Calouste Gulbenkian y de la Fundação Luso-Americana para o Desenvolvimento, durante el período 2012-2014. 
La hipótesis de esta investigación se apoya en la creencia de que, desde sus orígenes, el periodismo portugués en Estados Unidos no fue un fenómeno marginal, sino que tanto por el número de periódicos fundados como por su calidad y duración, la producción periodística portuguesa fue muy relevante en el desarrollo social, político, cultural y económico de la colonia lusa en Norteamérica, como ocurrió con otras comunidades de inmigrantes que ejercieron también su influencia sobre la sociedad norteamericana. Las cifras indican que en 1886 el número de cabeceras en lengua no inglesa en Estados Unidos era de 796; en 1900, alcanza los 1163; en 1917, 1323; en 1920, 1052; y en 1930, 1037 (Miller, 1987, p. 13). El período más productivo fue, por tanto, entre 1884 y 1920, en el que se fundaron 3444 periódicos, la mayoría de existencia efímera, que es uno de los rasgos que definen este tipo de prensa. Estadísticamente, como media, por cada 100 periódicos que se fundaban, 93 cerraban (Rhodes, 2010, p. 5-6).

El principal trabajo que ha registrado en esta época las cifras sobre la evolución histórica de los periódicos producidos por las comunidades de inmigrantes es el libro de Robert E. Park The Immigrant Press and Its Control (1922), en el que se demuestra que el fenómeno de la prensa étnica alcanza su máxima expansión en la etapa de la emigración masiva desde Europa, entre 1890 y 1930, cuando más de 22 millones de personas llegaron a Estados Unidos, sobre todo a través de los puertos de Nueva York y San Francisco (Park, 1922). En torno a 1910, había más de 1300 periódicos en lengua no inglesa (hasta en 30 lenguas diferentes), según el N.W. and Son's Ayer's American Newspaper Annual and Directory, de los cuales más de 500 eran en alemán, más de 100 en italiano, 75 en sueco y otros tantos en español. ${ }^{2}$ Aunque esta fuente no proporciona información sobre la prensa portuguesa, según los datos de esta investigación, en aquel año el número de periódicos en portugués ascendía a 12 títulos. En total, sumando todas las publicaciones étnicas editadas en todos los Estados, alcanzaban una tirada estimada de 2,6 millones de ejemplares, y cerca de 150 eran diarios (Bjork, 1998, p. 207).

Posiblemente, los medios de comunicación lusos contribuyeron a forjar la construcción de un imaginario cultural luso-americano y a proyectar su identidad en diversas regiones de Estados Unidos como hicieron otras comunidades de inmigrantes europeos (Rhodes, 2010), o las propias colonias de la emigración portuguesa en otras latitudes de América, especialmente en Brasil (Paulo, 2000)

2 N. W. and Son's Ayer's American Newspaper Annual and Directory. Pennsylvania: N. W. Ayer and Son, 1880-1909. 
o Argentina (Borges, 2009). Con el objetivo de conocer su influencia y relevancia, nos proponemos analizar los rasgos principales que definen la prensa lusoamericana: cuáles eran los títulos más populares, la estructura de su información y sus contenidos principales, los lugares de edición y el alcance de su difusión, los editores más destacados, entre otros elementos de interés.

\section{Rasgos generales de la producción periodística luso-americana}

En los periódicos fundados por los inmigrantes portugueses, está la más fiel radiografía de la colonia lusófona en Estados Unidos, integrada mayoritariamente por ciudadanos de origen azoriano (Warrin, 2010; Baganha, 1990; Pap, 1981; Cardozo, 1974). El estudio de este tipo de prensa revela un retrato integral, una honesta autoafirmación en la que se muestra con absoluta claridad cuál era la realidad política, social, lingüística, cultural y económica de los portugueses en territorio norteamericano: qué pensaban sobre ellos mismos y sobre su papel como inmigrantes en Estados Unidos; cómo veían a Portugal y a sus gobiernos; cómo vivían sus tradiciones a través de sus manifestaciones culturales; cómo se relacionaban con otras comunidades inmigrantes y con la cultura local dominante; cómo defendían sus derechos y su forma de vida; cómo promocionaban sus signos identitarios y su sentimiento patriótico; cómo enfocaban su propio relato informativo sobre todo lo que ocurría a su alrededor; cómo construían, en definitiva, su propio sueño americano (Rhodes, 2010). Quizás lo más característico de la prensa lusoamericana se refleje en los siguientes aspectos: 1) Es una prensa creada, salvo algunas excepciones (brasileiros y caboverdeanos), por inmigrantes de origen portugués, y la gran mayoría de sus fundadores y editores proceden de una única región de Portugal: el archipiélago de Azores. 2) Además de un interés especial por las informaciones relativas a los asuntos azorianos, debido a su vinculación a un país con un extenso imperio colonial es un tipo de prensa con intereses y preocupaciones universales, con noticias de carácter internacional. 3) La concentración migratoria en Massachusetts y California, con periódicos de referencia en estos dos Estados, como el Diario de Noticias (1927-1973) y el Jornal Português (1932-1997), la convierten en una prensa que tiene una marca territorial muy particular, presente también en Hawai, con una interesante influencia en las dos costas americanas.

La prensa portuguesa en territorio norteamericano es crucial para comprender la historia de la diáspora portuguesa a América. Los periódicos portugueses editados en Estados Unidos aportan abundantísima información sobre las actividades públicas de los inmigrantes portugueses en núcleos 
de población de numerosos Estados (Vicente, 1998). En la lectura de estas publicaciones se halla gran cantidad de datos sobre el proceso de evolución histórica de la colonia lusa que difícilmente se puede encontrar en ninguna otra fuente. Es una especie de microcosmos sobre todas las representaciones de la cultura luso-americana. No hay que olvidar que cada periódico ha sido un elemento de cambio social en su contexto; es decir, cada cabecera ejerció un papel, más o menos relevante, como actor político dentro de la comunidad. Muy probablemente, nunca la prensa portuguesa a lo largo de su historia tuvo un margen de libertad mayor para expresar todo aquello que los editores deseaban hacer saber al público.

El territorio norteamericano fue una especie de zona franca para escribir y publicar cualquier tipo de relato, más o menos periodístico, con más o menos destreza, fuera cual fuera la intención. No porque las autoridades de Estados Unidos no ejercieran algún tipo de control o censura sobre los medios impresos, algo que ocurrió en varias etapas históricas alegando razones de seguridad nacional, por ejemplo durante la Segunda Guerra mundial; sino porque, como la prensa luso-americana pasaba más inadvertida para las autoridades locales por ser escrita en otra lengua, fue sometida a un control menos riguroso que la publicada en inglés. Era, por decirlo coloquialmente, un territorio independiente que poco interesaba al gobierno de Estados Unidos. Como sus contenidos estaban en portugués, concernían casi exclusivamente a los inmigrantes. Por tanto, lo que ocurría dentro de la comunidad luso-americana, debía resolverse en el seno de la propia colonia. En este contexto, el poder y la influencia de algunos periódicos luso-americanos era enorme. Quien tenía un periódico, tenía un pequeño tesoro. Disponía de un fabuloso instrumento de poder para promocionar su negocio y sus ideas; para incrementar la notoriedad pública de sus amigos y colaboradores; para prestigiar determinadas actividades o instituciones; para hacer campañas a favor o en contra de algunos proyectos dentro de la colonia; para crear opinión acerca de todas las cuestiones que concernían o interesaban a los inmigrantes lusos; y, sobre todo si se hacía bien, el periódico podía incluso servir para lo más importante: para ganarse la vida dignamente. Lo que no era fácil. Porque, como señalaba João P. Brum, uno de los más populares empresarios periodísticos de la comunidad luso-californiana, el periodismo era un negocio que nadie quería: "fazer jornais era negócio de poetas, de idealistas, de tesos sem poderem com uma gata pelo rabo."3 Algunos, como el propietario del quincenario A California Alegre, afirmaba en su número

3 Notícia, n. 1, 5 de diciembre de 1984, p. 1. 
del 1-15 de enero de 1939 que los editores eran "[...] mártires do dever e do amor ao país onde nasceram [...]" (p. 4). Por eso, de forma recurrente muchos editores reivindicaban el servicio que sus periódicos prestaban a los inmigrantes, mientras se lamentaban del escaso apoyo que recibían. Todo por el bien de la colonia, "a bem da colonia", como repetían algunos de los editores. A Luta de New York lo expresaba así el 2 de febrero de 1938:

\begin{abstract}
A imprensa portuguesa é a alma da colónia! É ela que anuncia as nossas festas, defende os interesses dos nossos compatriotas, faz propaganda das colectividades, publica noticias da nossa Pátria, aviva o patriotismo, ventila questões locais e leva a través dos núcleos portugueses as notícias tristes dos que exalaram neste país o último sôpro de vida, longe da nossa terra que lhes serviu de berço. [...] Investiguem a existência de todos os jornais portugueses neste país, e encontrarão que a sua publicação é uma epopeia de sacrifícios, de desgostos e de desilusões, imolados no altar da Pátria e da Língua Portuguesa $[\ldots] .^{4}$
\end{abstract}

Los inmigrantes que decidían editar un periódico tenían cuatro grandes alicientes: proporcionaba poder, daba visibilidad en la comunidad, otorgaba prestigio $y$, si se gestionaba razonablemente bien, podía dar beneficios suficientes para vivir por medio de la publicación de anuncios. Así se explica que muchos inmigrantes, con escasísimos medios y falta de la preparación adecuada, decidieran publicar un periódico en su propia casa, cuya edición era, generalmente, efímera. En sus inicios, la mayoría de estos intrépidos editores eran tipógrafos con escaso conocimiento de las rutinas periodísticas y poca habilidad para escribir. Sin embargo, en determinado momento, fuera por un deseo de poner al servicio de la comunidad un medio de comunicación que sirviera para informar de lo que pasaba dentro de ella y en Portugal, para mantener vivo el portugués y sus valores culturales, o para sentirse parte de su grupo étnico, tomaron la decisión de convertirse en pequeños empresarios periodísticos. Hubo decenas de inmigrantes que formaron parte de este grupo de decididos propietarios, muchos sin demasiado éxito. Pero otros fueron lo suficientemente perseverantes para consolidarse e incluso alcanzar su sueño americano como editores de prensa portuguesa. En esta categoría entran poco más de una decena de inmigrantes portugueses, que consiguieron fundar varias

4 "A imprensa portuguesa é a alma da colónia". A Luta, New York City, 2 de febrero de 1938, p. 1. 
publicaciones periódicas cada uno de ellos. Entre los casos más destacados a lo largo de la historia, se encuentran figuras como António Maria Vicente, Arthur Vieira Ávila, João Rodrigues Rocha, Pedro Laureano Claudino da Silveira o João P. Brum. Todos tienen detrás una historia y una intrahistoria fascinante.

La producción periodística ha sido un factor que ha determinado o condicionado la evolución de la estructura política, social, cultural y económica de la sociedad luso-americana, una minoría étnica que ha ido desarrollando su singular identidad siguiendo códigos específicos de representación pública. Su ideología y su simbología están directamente relacionados con el discurso editorial y el pensamiento periodístico de los periódicos fundados en las múltiples ciudades donde se han ido estableciendo a lo largo del recorrido histórico de la inmigración portuguesa (Sousa, 2011). Por tanto, los periódicos luso-americanos son un medio excelente para descodificar eficazmente el discurso público general de la colonia portuguesa en Estados Unidos.

La prensa lusa fue un instrumento muy últil en el diseño de estrategias de promoción y protección de los intereses de los núcleos de inmigrantes, favoreciendo la cohesión social, el consenso político, la convergencia cultural y los proyectos asociativos de todo tipo. La colaboración entre los inmigrantes lusos, no sólo funcionó por medio de la fundación de instituciones o estructuras asociativas que promovían, entre las actividades más comunes, proyectos benéficos de carácter educativo o seguros sociales. Fue, principalmente, a través del discurso periodístico como la colonia consiguió crear una opinión pública con voz propia frente al discurso público anglosajón (Cuddy, 1982). Los emigrados crearon un sentimiento de pertenencia a una nueva sociedad que ellos mismos representaban dentro de Estados Unidos y difundieron los valores de un grupo social que gracias a la pujanza de su prensa, conseguía proyectar mejor su imagen y hacerse má visible. De este modo, afirmaba su posición política, comercial y socio-cultural dentro de la compleja diversidad étnica de la sociedad norteamericana, particularmente en los Estados de Massachusetts y California, en los que los portugueses corrían el riesgo de ser fácilmente asimilados por el conjunto de minorías que los han ido poblando a lo largo de la historia (Holton \& Klimt, 2009; Mayone Dias, 2009; Barrow, 2002). Además, su repercusión mediática facilitaba la creación y consolidación de líneas de cooperación entre todos los núcleos de población de la comunidad luso-americana, con el objetivo estratégico de crear un movimiento social cohesionado que permitiera desarrollar proyectos comunitarios y hacerse más fuertes dentro del tejido social norteamericano. 
En los periódicos editados en portugués, los inmigrantes encontraron un medio de vinculación emocional con sus orígenes a través de la lectura de las noticias sobre la realidad portuguesa; y también muchas informaciones sobre lo que ocurría dentro de la comunidad luso-americana. En ocasiones, lo que los emigrados buscaban en este tipo de publicaciones era, simplemente, la emoción espiritual que alimentaba el sentimiento de pertenencia a la colonia a través del signo identitario y cultural más esencial: la lengua. Al igual que ocurrió con la mayoría de las comunidades de inmigrantes (Rhodes, 2010), los periódicos en portugués daban un sentido trascendente, a través de una retórica generalmente cargada de un lenguaje patriótico, a la existencia y presencia de cada uno de los emigrados en Estados Unidos. Aunque el índice de inmigrantes lusos analfabetos fuera elevado, principalmente entre los que emigraron a finales del siglo XIX y durante el primer tercio del siglo XX (Williams, 2007, p. 3782), es muy probable que la necesidad de mantener el contacto con la realidad cultural portuguesa estimulara el aprendizaje de la lectura entre ellos (Bartoli, 1996). Más allá de otras consideraciones de carácter utilitarista, probablemente una de las motivaciones más importantes para leer la prensa portuguesa, era no perder su identidad lusófona, no dejar de ser y de representar su significación cultural.

Por otro lado, las publicaciones editadas por los inmigrantes jugaron un papel muy interesante como agentes de dinamización económica dentro de la colonia luso-americana, pues eran un soporte de comunicación perfecto para los comerciantes e industriales que consiguieron abrir un pequeño negocio local y que querían promocionar sus productos o servicios entre sus coterráneos, sus principales clientes. Anuncios de supermercados, de tiendas de ropa, zapaterías, hostales, funerarias, panaderías, peluquerías, entre otras empresas propiedad de portugueses, buscaban atraer a la clientela lusa apelando a la confianza que proporcionaba pertenecer a la misma cultura, hablar la misma lengua y compartir la condición de inmigrantes en América. La apelación al patriotismo fue, también, una constante entre los anunciantes portugueses que se dirigían a la comunidad desde los periódicos luso-americanos. Por supuesto, la prensa inmigrante ejerció también una representación política y comercial, en la medida que los órganos de comunicación de la colonia se convirtieron en representantes de los intereses de una minoría dentro de la cultura local, al tiempo que ofrecía sus páginas para que los comerciantes o políticos nativos pudieran dirigirse a los inmigantes luso-americanos para sus campañas publicitarias o propagandísticas. 
El valor documental de las noticias sobre el acontecer cotidiano en las diferentes localidades con población portuguesa en Estados Unidos, concentrada fundamentalmente en Massachusetts y California, es enorme. Por medio de estas fuentes hemerográficas, se puede comprender el nivel de integración social de los inmigrantes en los diferentes contextos históricos y territorios; evaluar su capacidad de adaptación al entorno socio-cultural anglosajón; conocer cuáles eran los principales líderes públicos de la comunidad luso-americana; descubrir qué empresarios o empresas creadas por inmigrantes eran relevantes; averiguar las tendencias de la opinión pública sobre la política norteamericana, portuguesa o internacional; conocer cuáles eran los símbolos identitarios más utilizados; seguir la evolución en el uso de la lengua portuguesa; investigar qué nivel de influencia tenían estes periódicos en la sociedad local norteamericanna etc. Cada periódico publicado por los inmigrantes luso-americanos es, en este sentido, una fuente de información excepcional.

\section{Las primeras publicaciones periódicas en portugués, 1877-1889}

Las primerasmanifestacionesperiodísticas producidas por los portugueses en Norteamérica de las que se tiene registro, datan de finales del siglo XIX. Entre 1877 y 1900, en los Estados de Massachusetts, California y Hawai se publicaron 33 títulos en portugués. En esta época, varias comunidades de portugueses se habían establecido en Estados Unidos, principalmente concentradas en varias zonas de los Estados de Nueva Inglaterra y en algunos territorios californianos y hawaianos. Durante este período histórico, los grupos de inmigrantes comenzaron a organizarse en sociedades fraternales, instituciones relacionadas con la beneficiencia, clubes de recreo o asociaciones de todo tipo en los diferentes lugares en los que se fueron arraigando. Los presidentes y directores de estas organizaciones, junto con los sacerdotes, pronto se convirtieron en las figuras públicas más relevantes de las comunidades. Pero a medida que el fenómeno periodístico fue adquiriendo una importancia mayor, con la creación de una opinión pública propia dentro de la colonia, los editores y periodistas se transformaron en líderes naturales con gran capacidad para influir políticamente (Gomes, 1995). En términos cuantitativos, agrupando de forma cronológica (por décadas y Estados) el número de publicaciones periódicas fundadas, el nacimiento y desarrollo de este fenómeno periodístico luso-americano nos ofrece las siguientes cifras:

- 1870: 1 (Pennsylvania) 
- 1880: 8 (2, Massachusetts.); (4, California); (2, Hawai).

- 1890: 24 (9, Massachusetts); (8, California); (7, Hawai).

- 1900: 16 (9, Massachusetts); (5, California); (2, Hawai).

Como ya se ha referido en la introducción, la primera publicación periódica en portugués editada en Estados Unidos de la que se tiene conocimiento es el semanario $O$ Jornal de Noticias, que fue fundado en 1877 en Erie (Penn.). Su fundador y primer editor fue John (João) Maria Vicente, que se había establecido en Boston tras trabajar en un barco ballenero, e inició su proyecto periodístico con la ayuda de su hijo mayor, António Maria, ambos originarios de la isla de Flores (Azores) (Pap, 1987, p. 294). La familia Vicente había llegado a Erie como miembros de una pequeña comunidad de portugueses que se sintieron atraídos por el desarrollo económico de la pequeña ciudad al borde del lago del mismo nombre, impulsado por la industria del ferrocarril y el transporte de mercancías. Erie era entonces una estación importante, cruce de varias lineas ferroviarias hacia Canadá y el Oeste, con puestos de trabajo y posibilidades de negocio para los recién llegados (Pap, 1981, p. 35-53).

O Jornal de Noticias se publicó hasta 1884, cuando António Maria Vicente, que se había hecho cargo del periódico a la muerte de su padre, decidió emigrar a California para continuar con otros proyectos periodísticos. Al igual que ocurrió en otros muchos lugares donde se fundaron periódicos en portugués en el siglo XIX, O Jornal de Noticias comenzó como un proyecto asociado a una tipografía. John (João) Maria Vicente había fundado en Erie una empresa tipográfica, que heredaron sus hijos con el nombre de John M. Vicente's Son's. El periódico era un importante medio para promocionarla, así como para conseguir ingresos extra por medio de los anuncios publicitarios. La información estaba distribuída en pequeñas secciones dedicadas a noticias breves sobre las diferentes islas de Azores, composiciones de carácter lírico, artículos sobre asuntos relacionados con la actualidad o de carácter histórico, sobre celebraciones, natalicios, obituarios etc. El director y redactor principal del Jornal de Noticias era António Maria Vicente. A través de avisos se solicitaba la colaboración de los lectores para la publicación de las noticias con el siguiente mensaje:

Quando algum dos nossos leitores tiver conhecimento de um ocorrido qualquer entre os nossos patricios: um casamento, óbito, desastre, o que quer que seja, rogamos que nos dê notícias do mesmo o mais 
breve possível, pelo que será muito agradecido. O que exigimos é so os factos e data, e cá arranjaremos um artigo sobre o mesmo. Não receiem de escrever o que souberem. ${ }^{5}$

El directorio de prensa americano de Geo P. Rowel \& Co., editado en Nueva York, describe en su edición de 1878 al Jornal de Noticias en los siguientes términos: "Saturdays; Portuguese; four pages; size 20x26; subscription \$2, established 1877; J. M. Vicente, editor and publisher" (Geo P. Rowell \& Co. 1878, p. 275). Su difusión no alcanzaba únicamente el territorio de Estados Unidos, gracias a la fácil distribución que permitían las conexiones ferroviarias desde Erie, sino que también se enviaba a Azores y Portugal continental. La llamada "Pennsylvania Railroad" unía los puertos del Atlántico con todos los Estados occidentales y Canadá. ${ }^{6}$ Como la mayoría de las publicaciones editadas en portugués en Estados Unidos a lo largo de la historia, O Jornal de Noticias concedía gran relevancia a las celebraciones relacionadas con los símbolos de Portugal. En su edición del 24 de julio de 1880 (n. 140), dedica su portada casi íntegramente al tricentenario del nacimiento de Luis de Camões. Reproduce estrofas del ilustre escritor portugués y publica varios artículos con noticias relacionadas con la conmemoración en Estados Unidos. Según cuenta el propio periódico, su publicación tuvo un gran impacto en la comunidad portuguesa, tanto dentro como fuera de las fronteras americanas. ${ }^{7}$ A causa a los escasos recursos humanos, este tipo de prensa tenía grandes limitaciones para conseguir noticias y artículos originales. Algunas noticias, especialmente las internacionales, eran resumidas en una sección denominada "Telegraphico!". Gracias a la publicación de anuncios de hoteles y hospederías portuguesas se ha podido saber que el periódico era leído en otras ciudades de la Costa Este, como Boston.

O Jornal de Noticias fue el primer periódico de una serie de publicaciones portuguesas que surgieron a lo largo del territorio norteamericano en el último cuarto del siglo XIX, localizadas en los lugares donde se fueron estableciendo diferentes núcleos de población de inmigrantes portugueses. En San Francisco, el 5 de agosto de 1880, se fundó el segundo periódico en portugués más antiguo de Estados Unidos, el semanario $A$ Voz Portugueza, editado por un inmigrante brasileiro (posiblemente de ascendencia portuguesa), Manoel Stone. Algunos autores han atribuído la fundación de este periódico a António Maria Vicente

5 Jornal de Noticias, $4^{\circ}$ año, n. 173, 12 de febrero de 1881, p. 6

6 O Jornal de Noticias, n. 144 (3० año), 24 de julio de 1880, p. 4.

7 O Jornal de Noticias, n. 173 (ano 4), 12 de febrero de 1881, p. 1. 
(Holmes \& D'Alessandro, 1990, p. 158; Vaz, 1965, p. 142). Pero lo cierto es que, en el primer ejemplar de $A$ Voz Portuguesa que se guarda en la Library of Congress, figura Manoel Stone como "publisher". También se ha especulado con la posibilidad de que el ideólogo del proyecto editorial hubiera sido António Maria Vicente. Pero el dato del número inaugural vendría a zanjar cualquier debate sobre esta cuestión.

\section{La afirmación del periodismo portugués en California y Massachusetts, 1890-1909}

Las dos décadas que van de 1890 hasta 1909 fueron una etapa en la que el periodismo en portugués en Estados Unidos se revela como un fenómeno en proceso de consolidación. La corriente migratoria de Portugal hacia territorio norteamericano sigue creciendo y esto empuja a ciertos inmigrantes, con conocimientos tipográficos o con formación intelectual a explorar la posibilidad de crear empresas periodísticas. La demanda de información en portugués era creciente debido a que la gran mayoría de los emigrantes carecían de conocimientos de inglés y tenían una perentoria necesidad de información sobre su lugar de origen y destino, como ya se ha analizado más atrás. Es un período en el que, según los datos del repositorio de este estudio, se fundaron 40 publicaciones periódicas. La mayoría fueron efímeras, pero algunas demostraron que eran capaces de hacerse un hueco perdurable en el periodismo étnico americano. Además del caso de los periódicos luso-hawaianos y del sucesor de $O$ Arauto, en California y Massachusetts surgieron proyectos periodísticos sólidos, como O Repórter (Oakland, San Francisco, 1897-1916), A Liberdade (Sacramento, 1900-1937) O Independente (New Bedford, 1897-1945), Alvorada (1909-1923?) y Novidades (New Bedford, 1907-1948).

Entre 1880 y 1909, se editaron en California un total de 16 periódicos, además del Boletim da União Portuguesa do Estado de California, 8 de los cuales vieron la luz durante la década de 1890. Junto con la década de 1930, fue una de las etapas históricas más fructíferas en el número de títulos fundados en ese Estado. Fue una época de aprendizaje cultural para los inmigrantes, dentro de un proceso de integración social que no siempre fue fácil. California era un Estado que estaba creciendo demográficamente muy rápido con una estructura social multiétnica, multicultural y multilingüística, con creencias religiosas y afinidades ideológicas diversas. La masiva llegada de inmigrantes de diversas procedencias y maneras de entender la convivencia en comunidad provocaban malentendidos que podían derivar en enfrentamientos. Las actitudes racistas y la intolerancia religiosa no eran extraños en una sociedad que se estaba 
forjando, tanto en sus leyes como en sus convencionalismos. Era una etapa en la que, además, las estructuras políticas y las relaciones laborales necesitaban adaptarse a este nuevo contexto. Eran tiempos de cambio, de debate político, como mostraban los contenidos de los periódicos luso-americanos (Gomes, 1995, p. 17-44).

La pugna dentro de cada comunidad inmigrante por el liderazgo era algo habitual, y la prensa era el medio más eficaz para hacer propaganda de los postulados ideológicos de cada grupo social. En el caso portugués, el republicanismo contra el monarquismo, el clericalismo contra el anticlericalismo, o los partidarios o contrarios a determinadas políticas en las sociedades fraternales, eran ejemplos de temas que suscitaban polémicas de forma recurrente. En algunos casos, los debates se llevaban al terreno personal y se producían rifirrafes que adquirían una dimensión pública por el efecto amplificador de la prensa, como el que enfrentó al exiliado republicano Mário Bettencourt da Câmara con Guilherme Silveira da Gloria. Las críticas al catolicismo del primero en su etapa como redactor-jefe de A União Portuguesa fueron objeto de ataques del segundo desde $O$ Amigo dos Cathólicos. La polémica continuó durante años. En el primer número de la revista crítica y satírica $A$ Chrónica, que Mário Bettencourt da Câmara editó en San Francisco desde el 6 de julio de 1895, retomó la disputa con Guilherme Gloria con un editorial dirigido “ao povo portuguez" en el que acusa al sacerdote de pretender aumentar su popularidad a su costa. ${ }^{8}$

Hubo otros periódicos luso-americanos publicados en California en este período finisecular. Estos eran: A Pátria, que Manoel Stone imprimía irregularmente en Oakland entre 1891 y 1897; O Eco Açoreano, dirigido en San Francisco por Constantino C. Leal Soares en 1890; O Progresso, editado por Frank Silva en 1894; y el Nova Pátria, de Oakland. En estos años nace el proyecto editorial más longevo de las publicaciones periódicas luso-americanas, el Boletim da União Portuguesa do Estado da California, institución que fue fundada el 1 de agosto de 1880, editado desde el 1 de marzo de 1898 hasta enero de 2010, con una interrupción entre 1967 y 1968. ${ }^{9}$ El Boletim da UPEC comenzó su impresión con una tirada de 2500 ejemplares, que se fue ampliando a

8 A Chrónica, n. 1, 6 de julio de 1895, p. 1 y 2.

9 Su sede fue cambiando a lo largo del tiempo. Se fundó en San Francisco, y luego se traslada a San Leandro (en 1124 E 14th Street). En los años treinta y cuarenta, la publicación se editaba en Atwater. En septiembre de 1950, su sede se trasladó a Oakland (735 Chesnut Street). Más tarde, la sede regresa a San Leandro. 
medida que se incrementó el número de socios de la entidad. ${ }^{10}$ Fue mensual, trimestral y semestral en diferentes períodos históricos, con un formato variable, generalmente de proporciones reducidas e ilustrado, tipo magazine. ${ }^{11}$ Su lengua era el portugués, pero utilizaba ocasionalmente el inglés en algunos artículos.

Además del longevo proyecto del Boletim da UPEC,en los inicios del siglo XX surgieron nuevos proyectos periodísticos en California, todos ellos fugaces, como el semanario de San Jose A Semana Portugueza (1903) y la revista A Crítica Literaria, ambos fundados por Joaquim Borges de Menezes; la revista de Pedro L. C. da Silveira Portugal-América (1905) con sede en Fresno; y A Voz da Verdade (1908-1909), en Oakland. La única empresa que logró consolidarse, además de $A$ União Portuguesa y O Arauto, fue el periódico que haría popular a Guilherme Silveira da Gloria en la colonia, A Liberdade, que se publicaría entre 1 de octubre de 1900 y 1937, primero en Sacramento (hasta 1920), y después en Oakland. En esta nueva ciudad, durante varios años se imprimió de forma diaria. En 1926, A Liberdade informa que es el único diario portugués de California y se promociona incluyendo el siguiente mensaje en la cabecera: "We reach all the Portuguese population in the Pacific coast. There are more than 100,000 in the state of California; one third in the Bay Cities; 18,000 in Greater Oakland. Advertise in this paper if you wish to secure the Portuguese trade. They like to read your'ads'in their own language". Habitualmente, en los años treinta utilizaba también la frase: "Dedicado aos interesses da colonia portuguesa na California". En diciembre de 1934, aparece en la cabecera un nuevo lema promocional: "O Jornal de maior circulação entre os portugueses da Califonia e Hawai". ${ }^{2}$

A Liberdade fue dirigida y redactada de forma personal por Guilherme S. Gloria, quien en sus artículos solía hacer referencia a las grandes figuras y mitos de la historia de Portugal para aumentar el sentido pedagógico de sus textos. ${ }^{13}$ El prematuro fallecimiento de su hijo y la inesperada pérdida de su esposa, obligó a Guilherme S. Gloria a cerrar A Liberdade. Antes de clausurar su periódico, el poeta y periodista portugués intentó encontrar un comprador publicando anuncios en los que explica que el cierre se debía a su vejez y su soledad: “[...] Esta venda torna-se necessária, devido a minha idade avançada,

10 Véase el Jornal Português, n. 191,14 de febrero de 1936, p. 1.

11 El Boletim da U.P.E.C. experimentó diversos cambios en su tamaño, número de págimas y en el diseño informativo a lo largo de su historia. Su formato estándar ha sido siempre de proporciones reducidas, ilustrado a partir de los años treinta. Desde enero de 1968, bajo la coordinación de Carlos Almeida (que se convierte en su editor), el Boletim moderniza su diseño tipográfico, en color y con una mayor calidad en el papel. Véase: Boletim da U.P.E.C., vol. LXVII, n. 1.

12 A Liberdade, n. 3274 (año 34), del 29 de diciembre de 1934.

13 A Liberdade, n. 3257 (año 34), 7 de julio de 1934, p. 2. 
e principalmente pelo meu estado de depressão ocasionado pela irreparável falta da minha esposa, que era a alma deste negócio, e pela perda dolorosa do meu filho, única esperança que me restava na amárga e escabrosa senda da vida $[. . .]^{\prime \prime}{ }^{14}$

En Massachusetts, fueron 18 las publicaciones periódicas que vieron la luz en este período histórico. En la década de 1890, entre las 9 cabeceras fundadas, salvo el caso de $O$ Independente, que se publicó desde 1897 hasta 1945, de O Novo Mundo, que duró 4 años, y de O Correio Portuguez,que duró más de 12 años, las demás cabeceras no pasaron del primer aniversario. Entre ellas estaban O Colombo (1892-1893), que fue creada por un tal Sr. Maciel durante la conmemoración del cuarto aniversario del descubrimiento de América; 0 Português (1893), publicado por varios sacerdotes católicos, los reverendos Martins, Neves, Claudio Vieira e Pimentel; A Verdade (1893), fundado por Francisco Gaetano Borges da Silva, que también editaría O Progresso en 1907; ${ }^{15}$ A Revista Portuguesa (1895), de Joaquim Borges de Menezes; ${ }^{16}$ el periódico para mujeres Jornal das Senhoras (1898), de Eugénio Escobar; ${ }^{17}$ y el semanario ilustrado Açôres-América (1903), con sede en Cambridge, creada por Eugénio Vaz Pacheco do Canto e Castro, ex profesor y rector del Liceu Antero de Quental, en Ponta Delgada (São Miguel, Azores), de la que sólo se editaron 13 números entre el 14 de febrero y el 16 de marzo de 1903, con algunos artículos en inglés firmados por Burton Holmes y difusión en Portugal y Brasil (Ponte, 2014). Con excepción de este último título, todas las publicaciones fueron editadas en New Bedford.

O Correio Portuguez se fundó el 15 de agosto de 1895 con el subtítulo "jornal dedicado á Colonia Portugueza na Nova Inglaterra". Según el directorio de prensa americano de H.W. Kastor \& Sons, O Correio Portuguez tenía una tirada media de 2500 ejemplares en 1906 (Kastor \& Sons, 1906, p. 167). Su fundador y editor durante sus primeros años, Manuel das Neves Xavier, publicaba

14 A Liberdade, n. 3344, (año 37), 3 de julio de 1937, p. 4.

15 Francisco Gaetano Borges da Silva, natural de São Miguel (Azores), editó el periódico de forma efímera. Sus contenidos estaban relacionados con la Iglesia Baptista en New Bedford, de la que formaba parte. Cuando vendió el semanario O Progresso a José Escobar, hijo de João Francisco Escobar, se transformó en diario varios meses.

16 A Revista Portuguesa fue fundada en New Bedford el 15 de agosto de 1895. Joaquim de Menezes, originario de la isla de Terceira (Azores), pronto abandonaría este proyecto para mudarse a California, donde dirigió O Amigo dos Cathólicos. Le sucedió el también azoriano Eugénio Escobar (hijo de João Francisco Escobar), que consigue editarla unos pocos números más.

17 El Jornal das Senhoras se editaba en New Bedford y estaba dirigido al público femenino. Tuvo una existencia fugaz. 
contenidos parecidos a los de su anterior periódico, A Civilização, con algunos artículos relacionados sobre la conducta moral. ${ }^{18}$

$O$ Independente fue uno de los mejores semanarios que ha tenido la colonia a lo largo de su historia. ${ }^{19}$ A pesar de los escasos ejemplares conservados, merecería un estudio monográfico por la riqueza de sus contenidos y por las vicisitudes históricas que lo han acompañado a lo largo de los casi cincuenta años de existencia en la "capital" de la colonia portuguesa en la Costa Este, New Bedford. Aunque se ha atribuído su fundación a João Francisco Escobar, ${ }^{20}$ fue fundado como quincenario el 30 de marzo de 1897 por Miguel F. Policarpo, con la ayuda de sus hermanos David y Joaquim. ${ }^{21}$ A partir del número 5, Frederico Pacheco Macedo se asocia a Manuel F. Policarpo y el periódico se convierte en semanario bajo la propiedad de Policarpos \& Cia. A los pocos meses, fue traspasado a la firma Bartholo \& Cia (propiedad del notario Alipio Coelho Bartholo ${ }^{22}$ y el sacerdote António Claudio Vieira), en la que Manuel F. Policarpo trabajó como tipógrafo e impresor. O Independente sería comprado posteriormente por los cónsules de Providence, Fall River, Boston y New Bedford, que pretendían convertirlo en un instrumento para sus campañas de propaganda y adoctrinamiento de los inmigrantes de Nueva Inglaterra. El proyecto fracasaría y, en noviembre de 1923, lo adquieren José M. Almeida y el tipógrafo António Fernandes Forte.

Junto a $O$ Independente,en esta época nació otro semanario muy destacado, As Novidades, o simplemente Novidades. Se funda el 14 de junio de 1907 y se publica hasta 1948. Aunque era un periódico de discurso católico, pues tanto su línea editorial como parte de sus contenidos estaban relacionados con las actividades de la Iglesia Católica, en realidad se trataba de un periódico que incluía muchas informaciones de carácter general y tenía vocación eminentemente popular. Según Vasco S. Jardim, su fundador fue Joaquim Braz, que era un farmacéutico originario de Goa. Manoel da Silveira Cardozo, sin embargo, atribuye su fundación a John (João) Baptista Machado (Cardozo,

18 O Correio Portuguez, año 1, n. 21, 4 de enero de 1896, p. 1.

19 O Independente tenía su sede en 157-A Acushnet Avenue (New Bedford).

20 Vasco de Sousa Jardim afirma en sus memorias que fue fundado por João Francisco Escobar. Véase el Luso-Americano, 25 de octubre de 1989, p. 39.

21 Diario de Noticias, n. 6922, 20 de febrero de 1942, p. 6.

22 Alípio Coelho Bartholo nació en Figueiro dos Vinhos, en la isla de Flores (Azores) y falleció en New Bedford el 24 de marzo de 1929. Emigró primero a California y luego a Nueva Inglaterra, donde trabajó como carpintero en Providence. Allí se casaría con Maria L. Souza. Aunque de origen humilde, se cultivó en el estudio de la lengua y la literatura portuguesa. Alípio C. Bartholo vendió su parte de $O$ Independente a su socio António Claudio Vieira. Fue el primer redactor del diario A Alvorada,fundado en 1919. Abandonó sus actividades de periodista por recomendación médica, debido a su diabetes. Desde entonces, se dedicó solamente a su profesión de notario. 
1974, p. 53). El Novidades mostró una especial preocupación por la situación de los sacerdotes en Estados Unidos. Al igual que otros periódicos de tendencia católica, como el californiano Jornal Português,defendía una mayor presencia de padres católicos para desarrollar una labor misionera en las comunidades portuguesas a lo largo del territorio americano. ${ }^{23}$

En esta etapa de inicios de siglo, de gran afluencia de inmigrantes a New Bedford, hubo otros títulos que tuvieron una corta existencia o que se editaron irregularmente. Entre ellos, están el Jornal Português, fundado por Manuel Benevides Raposo en 1901; la revista Aurora Luzitana, editada por Manuel das Neves Xavier entre 1900 y 1901; O Semeador, publicado por Augusto B. Pimentel de 1906 a 1909; O Progresso, dirigido en 1907 por Francisco Gaetano Borges da Silva y por José Escobar; y A Pátria, título editado por Avelino de Abreu en 1909 y reeditado por el madeirense Carlos Alberto Supico (Mendonça, 2007, p. 341), ${ }^{24}$ exredactor de O Independente, en la tipografía del Diario de Noticias entre 1935 y $1936 .{ }^{25}$ En 1909, el reverendo protestante Francisco Gaetano Borges da Silva inicia también la edición de un nuevo semanario religioso, Alvorada, que se publicará hasta el inicio de los años veinte.

\section{Conclusiones}

Desde finales del siglo XIX, la comunidad inmigrante portuguesa en los Estados Unidos ha desarrollado una importante actividad periodística a través de la fundación de decenas de publicaciones periódicas que han contribuído decisivamente a crear y desarrollar el imaginario social, cultural y político lusoamericano. De acuerdo con los datos de archivo encontrados, el periodismo luso-americano se inició en 1877 en Erie (Pennsylvania), cuando António Maria Vicente decidió fundar el semanario Jornal de Noticias, que fue el primero de una serie de 49 cabeceras impresas que nacieron en los Estados de Massachusetts, California y Hawai hasta 1910, la mayoría de duración efímera. Algunos de estos periódicos fueron fundados por tipógrafos portugueses que encontraron en la prensa una nueva oportunidad de negocio, que además incrementaba su

23 "As igrejas portuguesas necessitan de padres!...." Artículo de J. Marques Jardim. Jornal Português, n. 1127, 28 de mayo de 1954, p. 1.

24 António G. Faria fue el administrador del proyecto. Carlos Alberto Supico comenzó su carrera como periodista trabajando en $O$ Independente entre el 23 de febrero de 1925 y noviembre de 1926. Luego, partiría hacia New York, donde trabajaría en un comercio. Años más tarde regresaría a New Bedford para trabajar como redactor en el Diario de Noticias, actividad que inicia el 7 de octubre de 1935.Colaboró también con el periódico humorístico O Pé do Vento y con el madeirense Eco do Funchal.

25 A Patria era un semanario con formato tipo sábana, ilustrado con fotografías, de 4 páginas de extensión media, con una línea informativa favorable a la dictadura del Estado Novo. 
influencia pública, realizaba un servicio informativo a la comunidad y servía para desarrollar un sentimiento de cohesión y consenso entre los inmigrantes. Otras publicaciones estuvieron vinculadas al movimiento católico u otras confesiones religiosas, que aprovecharon el potencial propagandístico de la prensa para difundir su credo. Pero entre sus rasgos más distintivos, este tipo de prensa fue un agente que contribuyó de modo relevante a la cohesión social, el progreso económico y la proyección pública de la comunidad inmigrante portuguesa en Norteamérica.

\section{REFERÊNCIAS}

BAGANHA, M. loannis. Portuguese Emigration to the United States, 1820-1930. New York: Garland Publishers, 1990.

BARROW, C. W. (ed.). Portuguese Americans and Contemporary Civil Culture in Massachusetts. North Dartmouth: Tagus Press, Center for Portuguese Studies and Culture-University of Massachusetts Dartmouth, 2002.

BARTOLI LANGELI. Attilio. Historia del analfabetismo y método cuantitativo. Signo. Revista de Historia de la Cultura Escrita, n. 3, p. 87-106, 1996.

BJORK, Ulf Jonas. Ethnic Press. Newspapers for non-English speakers have long history. In: History of the Mass Media in the United States: An Enciclopedia. Edited by Margaret A. BLANCHARD (Commisioning editor Carol J. Burwash). ChicagoLondon: Fitzroy Dearbon Publishers, 1998.

BORGES, Marcelo. Portuguese Migration to Argentina in Transatlantic Perspective. Leiden: Koninklijke, 2009.

CARDOZO, M. S. The Portuguese in America, 590 b. C.-1974: a chronology \& fact book. Dobbs Ferry, New York: Oceana Publications, 1974.

CORREIA, Rui Antunes. Salazar in New Bedford: Political Readings of Diario de Noticias, the only Portuguese daily newspaper in the United States. In HOLTON, Kimberly Dacosta \& KLIMT, Andrea (eds.). Community, Culture and The Makings of Identity: Portuguese-Americans along Eastern Seabord. North Dartmouth: Tagus Press, Center for Portuguese Studies and Culture-University of Massachusetts Dartmouth, p. 227-247, 2009.

CUDDY, D. L. (ed.). Contemporary American Immigration: Interpretative Essays (European). New York: Twayne Publications, 1982.

GALLOWAY, J. H. The Sugar Cane industry: An historical geography from its origins to 1914. Cambridge: Cambridge University Press, 1989. 
GOMES, Geoffrey. "The Portuguese Language Press in California: The Response to American Politics, 1880-1928". Gávea-Brown: A Bilingual Journal of Portuguese American Letters and Studies, vols. XV-XVI, p. 5-90, Jan. 1994-Dec.1995.

HOLMES, L. \& D'ALESSANDRO, J. Portuguese Pioneers of the Sacramento Area. Sacramento (California): Portuguese Historical \& Cultural Society, 1990.

IRELAND, S. L. J. Ethnic Periodicals in Contemporary America: an annotated guide. New York: Greenwood Press, 1990.

KASTOR, H. W. \& Sons. Newspaper and Magazine Directory. Chicago-St. Louis and Kansas City: Published by H.W. Kastor \& Sons Advertising Co, 1906.

KNOWLTON, Edgar. "The Portuguese Language Press in Hawaii". Social Process in Hawaii, 24, p. 89-99, 1960.

MAYONE DIAS, Eduardo. The Portuguese Presence in California. San Jose (Calif.): Portuguese Heritage Publications, 2009.

MENDONÇA, Duarte Miguel Barcelos. Da Madeira a New Bedford: um capítulo ignorado da emigração portuguesa nos EUA. Funchal: Direcção Regional dos Assuntos Culturais, 2007.

MILLER, Sally. (ed.). The Ethnic Press in the United States: A Historical Analysis and Handbook. New York-West Port-Connecticut-London: Greenwood Press, 1987.

N. W. \& Son's Ayer's American Newspaper Annual and Directory. Pennsylvania: N. W. Ayer \& Son's, 1880-1909.

PAP, Leo. The Portuguese-Americans. Boston: Twayne Publishers-A Division of G. K. Hall \& Co. (The Immigrant Heritage of America Series, Cecyle S. Neidle, Editor), 1981.

The Portuguese Press. In: MILLER, Sally. (ed.). The Ethnic Press in the United States: A Historical Analysis and Handbook. New York-West Port-ConnecticutLondon: Greenwood Press, p. 291-302, 1987.

PARK, Robert E. The Immigrant Press and its Control. New York: Harper \& Brothers, 1922.

PAULO, Heloisa. Aquí também é Portugal: a colónia portuguesa do Brasil e o salazarismo. Coimbra: Quarteto, 2000.

PENA, Alberto; MESQUITA, Mário; VICENTE, Paula (coords.). Galiza e os Açores - A Rota Americana. Lisboa: Almedina-Fundação Luso-Americana \& Consello da Cultura Galega, 2012.

. Emigración e exilio nos Estados Unidos: experiencias de Galicia e Azores. Santiago de Compostela: Consello da Cultura Galega, 2015. 
PONTE, L. Percursos Identitários na Diáspora Açoriana: o Jornal Açores-Amérrica (1903). Interdisciplinary Jornal of Portuguese Diaspora Studies, v. 3.1, p. 221-246, 2014.

RHODES, Leara.The Ethnic Press: Shaping the American Dream. New York: Peter Lang, 2010.

ROWELL, Geo P. \& Co. American Newspaper Directory. New York: Geo P. Rowell \& Co. Publishers, 1878.

DOI: https://doi.org/10.3726/978-1-4539-0015-4

SOUSA, Jorge Pedro e outros. O Pensamento Jornalístico Português: das origens a Abril de 1974. (2 vols.). Covilhã: Livros LabCom-Universidade da Beira Interior, 2011.

VAZ, A. M. The Portuguese in California. Oakland: IDES Supreme Council, 1965.

VICENTE, Luis A. Os Portugueses nos Estados Unidos da América: Política de Comunidades e Comunidade Política. Lisboa: Fundação Luso-Americana para o Desenvolvimento, 1998.

WARRIN, Donald. So Ends This Day: The Portuguese in American Whaling, 1765-1927. North Dartmouth: Tagus Press, Center for Portuguese Studies and CultureUMass Dartmouth, 2010.

WILLIAMS, Jerry. In Pursuit of Their Dreams: A History of Azorean Immigration to the United States. North Dartmouth: Tagus Press, Center for Portuguese Studies and Culture-University of Massachusetts Dartmouth, 2007.

Recebido em: 18/10/2016

Aceito em: 18/10/2016

Endereço do autor:

Alberto Pena Rodriguez <alberto@uvigo.es>

Faculdade de Ciências Sociais e da Comunicação na Universidade de Vigo

Campus Universitario da Xunqueira, $\mathrm{s} / \mathrm{n}^{\circ}$

36005 - Pontevedra - Espanha 